\title{
Neuropsychological effects of escitalopram treatment in
} middle-aged women

\author{
Atalie Rasgon*, Laurel Zappert, Tonita Wroolie, Katherine Williams, \\ Jennifer Keller, Stephanie Shelton, Heather Gumina and Margaret Reynolds
}

Address: Stanford Universtity School of Medicine, USA

* Corresponding author

from International Society on Brain and Behaviour: 2nd International Congress on Brain and Behaviour

Thessaloniki, Greece. 17-20 November 2005

Published: 28 February 2006

Annals of General Psychiatry 2006, 5(SuppI I):SI 88 doi:I0.II86/I744-859X-5-SI-SI88

\section{Background}

This study assessed mood and neuropsychological changes in a population of middle-aged depressed women treated with escitalopram.

\section{Materials and methods}

18 women between the ages of 45-65 with a DSM-IV diagnosis of major depression were consecutively enrolled in the study at Stanford University School of Medicine, Department of Psychiatry and Behavioral Sciences. All women were treated with escitalopram in an open label design. Women were recruited from the community. All but three were Caucasian. Mean age was 55.94 and mean number of years of education was 16.36. Mood and cognition were assessed at baseline and 3-months post-treatment. Mood was assessed with the Hamilton Rating Scale for Depression (HRSD). The neuropsychological battery included the Wechsler Memory Scale-Third Edition (WMS-III), Wechsler Abbreviated Scale of Intelligence, and Trail Making Test Parts A and B.

\section{Results}

Statistically significant differences (improvements) were found in total HRSD score $(95 \%$ CI, p < 0.000), HRSD endogenous symptoms (95\% CI, p < 0.000), WMS-III Logical Memory II total score ( $95 \% \mathrm{CI}, \mathrm{p}=0.003)$, WMSIII Visual Reproduction I total score $(95 \% \mathrm{CI}, \mathrm{p}=0.025)$, and Trails B $(95 \% \mathrm{CI}, \mathrm{p}=0.017)$.

\section{Discussion}

Treatment of depression with escitalopram in a population of middle aged women was shown to improve mood and cognitive efficiency in select cognitive domains. 